\title{
Sodium intake in men and potassium intake in women determine the prevalence of metabolic syndrome in Japanese hypertensive patients: OMEGA Study
}

\author{
Tamio Teramoto ${ }^{1}$, Ryuzo Kawamori ${ }^{2}$, Shigeru Miyazaki ${ }^{3}$ and Satoshi Teramukai ${ }^{4}$, for the OMEGA Study \\ Group $^{5}$
}

Dietary intake affects hypertension and metabolic syndrome (MS) and their management. In Japanese hypertensive patients, little evidence exists regarding the relation between diet and MS. A self-administered lifestyle questionnaire was completed by each patient at the baseline. Three dietary scores were calculated for each patient: sodium intake, potassium intake and soybean/fish intake. The relationships between dietary scores and systolic blood pressure (SBP) and diastolic blood pressure (DBP) were analyzed by multiple regression analysis. The relation between dietary intake of sodium, potassium and soybean/fish, and the presence of MS was evaluated by the Mantel-Haenszel test. A total of 9585 hypertensive patients (mean age, 64.9 years; women, $51.4 \%$ ) were included in this sub-analysis. High sodium intake was significantly related to increased SBP $(P=0.0003)$ and DBP $(P=0.0130)$. Low potassium intake was significantly related to increased SBP $(P=0.0057)$ and DBP $(P=0.0005)$. Low soybean/fish intake was significantly related to increased SBP $(P=0.0133)$. A significantly higher prevalence of MS was found in men in the highest quartile of sodium intake compared with the lower quartiles $(P=0.0026)$ and in women in the lowest quartile of potassium intake compared with the higher quartiles $(P=0.0038)$. A clear relation between dietary habits and blood pressure was found in Japanese hypertensive patients using a patient-administered questionnaire. Sodium and potassium intake affect MS prevalence. Dietary changes are warranted within hypertension treatment strategies.

Hypertension Research (2011) 34, 957-962; doi:10.1038/hr.2011.63; published online 9 June 2011

Keywords: blood pressure; diet; essential hypertension; metabolic syndrome; prospective observational study

\section{INTRODUCTION}

An overwhelming body of evidence supports a direct relation between dietary sodium intake and elevated blood pressure (BP), and implies that reducing dietary sodium intake lowers BP. ${ }^{1-5}$ Elevated BP increases the risk of cardiovascular events as shown by a number of meta-analyses of large-scale clinical trials. ${ }^{6-9}$ Thus, restricted sodium intake is widely recommended for the management of hypertension. ${ }^{10-12}$ However, levels of sodium intake remain high in the Japanese general population. ${ }^{13}$

To date, little attention has been paid to the assessment of the sodium intake of the hypertensive individuals. Although there are several methods to assay dietary sodium intake, precise evaluation of this parameter is difficult; more reliable methods are difficult to perform (for example, measurement of urinary $\mathrm{Na}$ excretion by 24-h urine), and easier methods are less reliable (for example, evaluation of salt intake using test paper or salt sensor). ${ }^{14}$

According to Hoffmann and Cubeddu, ${ }^{15}$ a high dietary sodium intake can lead to the development of metabolic syndrome (MS).
However, Rodrigues et al. ${ }^{16}$ found no difference in urinary sodium excretion among normotensive individuals regardless of the presence of MS. Moreover, little is known about the relation between dietary habits and MS in Japanese patients with hypertension. The epidemiological evidence for the effects of potassium intake on blood pressure is inconsistent. ${ }^{12}$ On the other hand, soy protein and omega-3 polyunsaturated fatty acids, which are abundant in fish oil and fish, are effective for prevention of atherosclerotic cardiovascular diseases (CVDs). ${ }^{17-19}$

In this study, we investigated the relations between dietary habits and BP and MS in Japanese hypertensive patients using a selfadministered lifestyle questionnaire to assess the dietary intake of sodium, potassium and soybean/fish of each patient.

\section{METHODS}

Study design

The Olmesartan Mega Study to Determine the Relationship between Cardiovascular Endpoints and Blood Pressure Goal Achievement (OMEGA),

\footnotetext{
${ }^{1}$ Department of Internal Medicine, Teikyo University School of Medicine, Tokyo, Japan; ${ }^{2}$ Sportology Center, Juntendo University Graduate School of Medicine, Tokyo, Japan; ${ }^{3}$ Department of Internal Medicine, Tokyo Teishin Hospital, Tokyo, Japan and ${ }^{4}$ Division of Clinical Trial Design and Management, Translational Research Center, Kyoto University Hospital, Kyoto, Japan

${ }^{5}$ See Appendix.

Correspondence: Professor T Teramoto, Department of Internal Medicine, Teikyo University School of Medicine, 2-11-1 Kaga, Itabashi-ku, Tokyo 173-8605, Japan. E-mail: ttera@med.teikyo-u.ac.jp

Received 27 October 2010; revised 21 March 2011; accepted 22 March 2011; published online 9 June 2011
} 
a prospective, large-scale observational study, was designed to examine the relations between the incidence of CVD in Japanese hypertensive patients and their BP, the presence of MS, lifestyle factors, such as intake of high-salt foods, and other risk factors for CVD. The OMEGA study was initiated in September 2005 as a post-marketing surveillance study by Sankyo (presently Daiichi Sankyo, following company merger) in compliance with the Japanese Ministry of Health, Labor and Welfare regulations.

Details of the study design and baseline clinical characteristics of patients were published elsewhere. ${ }^{20}$ Briefly, eligible for inclusion were olmesartan (OLM)-naive men and women aged 50-79 years with physician-diagnosed hypertension who were receiving treatment in outpatient clinics. Excluded were patients with a history of myocardial infarction, stroke, coronary artery bypass graft surgery or percutaneous coronary intervention within 6 months before study enrollment, scheduled coronary intervention at study enrollment, congenital or rheumatic heart disease, severe arrhythmia, severe liver or renal disease, current cancer treatment and pregnancy or the potential to become pregnant. Each patient was informed of the purpose and methodology of the study, the right to withdraw from the study at any time and the measures taken for privacy protection. After providing written informed consent and being prescribed OLM, the patients were enrolled using a central electronic datacapturing system. This study was registered at http://www.clinicaltrials.jp/ with identification no. JapicCTI-050002. The study protocol was approved by the in-house ethics committee of Sankyo based on the pharmaceutical affairs law in Japan and was approved by the Ministry of Health, Labor and Welfare of Japan before commencement. This study was conducted in medical institutions registered according to the Good Post-Marketing Surveillance Practice in Japan and conformed to the Declaration of Helsinki.

\section{Study patients}

A total of 15313 patients from 2219 institutions across Japan were enrolled between July 2005 and March 2007. Here we report the data for 15118 case report forms, which were complete as of February 2009. Of these patients, data required to establish MS were missing in 4154 individuals. Dietary scores for 1215 patients and baseline BP for 164 patients were also missing. Thus, for this sub-analysis, the remaining 9585 patients were analyzed for assessment of the relations between dietary scores and BP and MS at baseline (Figure 1). In addition, 1009 patients with missing BP data at 6 months, dropout after the first visit, poor compliance, withdrawal of consent and no OLM administration were excluded; the remaining 8576 patients were analyzed for assessment of changes in SBP/DBP at 6 months compared with baseline.

\section{Dietary intake questionnaire}

Dietary intake, including volume and frequency, was self-reported by patients using a simple questionnaire containing questions on salt intake (salted fish intestines, dried fish, fish sausage, Japanese pickles, ham/sausage, traditional Japanese and Chinese soups with high salt content (noodle and miso soup), and use of salt and soy sauce) and on potassium intake (fruit) and soybeans/ fish intake (bean curd, non-salted fermented soybeans and fish). The high-salt foods were selected according to the 'Outline for the Results of the National Nutrition Survey Japan, 1997.' Although both fruit and vegetables contain high amounts of potassium, in this study, we assessed only fruit consumption because fruits tend to be eaten raw and retain their potassium, whereas vegetables may lose potassium content because of the heat in process of preparation. The soybeans foods were selected as Japanese traditional foods made from soybeans.

Frequencies of sodium, potassium and soybean/fish intake were classified into four groups, and scored as no intake (one point), intake once or twice weekly (two points), intake three to five times per week (three points) and intake every day (four points). When considering traditional Japanese and Chinese soups, frequencies and volume were separately investigated, and these intake scores were calculated from the square root of the product of the score of the intake frequencies multiplied by the score of intake volume. The sodium dietary score was total of the eight intake scores and ranged from 8 to 32 points. The potassium dietary score ranged from one to four points. The soybeans/fish intake score was a total of the three intake scores and ranged from 3 to 12 points (Table 1). The highest intake of sodium was defined as $\geqslant 20$ points ( $>75$ th percentile), and the lowest potassium and lowest soybeans/fish were defined as $<2$ and $<6$ points ( $<25$ th percentile), respectively.

\section{Estimated sodium intake}

The definition of the sodium dietary score used here has been shown to be related to excreted sodium content in urine. ${ }^{21}$ Estimated sodium intake (g per day) in this study was calculated using the formula from Arakawa et al. ${ }^{21}$ : $3.79+0.318 \times$ dietary score for men and $3.79+0.318 \times($ dietary score -2.82$)$ for women. On the basis of this formula, a 10-point increase in the sodium dietary score corresponds to an increased sodium intake of $3 \mathrm{~g}$.

\section{Diagnostic criteria for MS}

MS was defined according to the criteria established by the Japanese Society of Internal Medicine. ${ }^{22,23}$ Because all of our patients had hypertension, one

\begin{tabular}{|c|c|}
\hline \multicolumn{2}{|c|}{ Case report forms collected $(n=15118)$} \\
\hline \multicolumn{2}{|c|}{$\begin{array}{l}\text { Patients assessed for relationship between dietary } \\
\text { scores and blood pressure and metabolic syndrome } \\
\text { at baseline ( } \mathrm{n}=\mathbf{9 5 8 5} \text { ) }\end{array}$} \\
\hline \multicolumn{2}{|l|}{$\begin{array}{l}\text { Sodium score: } \geq 20(n=2696) \\
\text { Sodium score: }<20(n=6889)\end{array}$} \\
\hline \multicolumn{2}{|l|}{$\begin{array}{l}\text { Potassium score: } \geq 2(n=8722) \\
\text { Potassium score: } 1(n=863)\end{array}$} \\
\hline \multicolumn{2}{|c|}{$\begin{array}{l}\text { Soybean/fish score: } \geq 8(\mathrm{n}=5 \mathbf{5 0 7 4}) \\
\text { Soybean/fish score: }<8(\mathrm{n}=\mathbf{4 5 1 1})\end{array}$} \\
\hline \multicolumn{2}{|c|}{$\begin{array}{l}\text { Patients assessed for changes of SBP/DBP at } \\
\text { 6-month treatment below baseline level }(n=8576)\end{array}$} \\
\hline \multicolumn{2}{|l|}{$\begin{array}{l}\text { Sodium score: } \geq 20(n=2414) \\
\text { Sodium score: }<20(n=6162)\end{array}$} \\
\hline \multicolumn{2}{|l|}{$\begin{array}{l}\text { Potassium score: } \geq 2(n=7819) \\
\text { Potassium score: } 1(n=757)\end{array}$} \\
\hline $\begin{array}{l}\text { Soybean/fish score: } \geq \mathbf{8}(\mathbf{n}=4 \\
\text { Soybean/fish score: }<\mathbf{8}(\mathbf{n}=4\end{array}$ & $\begin{array}{l}4551) \\
4025)\end{array}$ \\
\hline
\end{tabular}

Figure 1 Flowchart of the OMEGA Study.
Patients not analyzed $(n=5535)$

No data for diagnosis of metabolic syndrome $(n=4154)$

No dietary score $(n=1215)$

No baseline blood pressure data $(n=164)$

\begin{tabular}{|l|}
\hline Patients not analyzed $(n=1009)$ \\
No blood pressure data at 6 months $(n=756)$ \\
Dropout after first visit $(n=97)$ \\
Poor compliance $(n=72)$ \\
Withdrew consent $(n=42)$ \\
Did not receive olmesartan $(n=42)$ \\
\hline
\end{tabular}




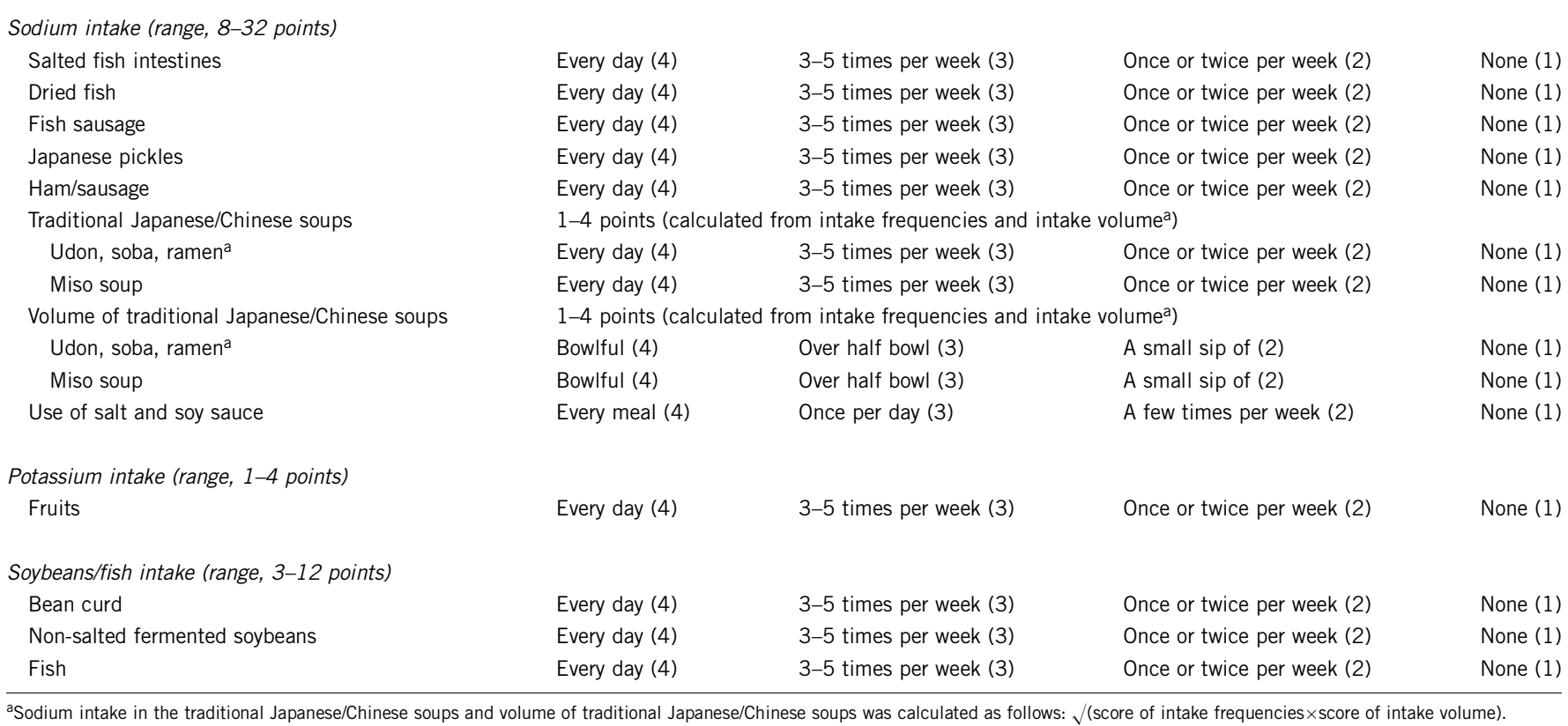

criterion of MS was fulfilled at study entry, and patients had to meet additional essential criteria for diagnosis of MS, such as the presence of central obesity with a waist circumference $\geqslant 85 \mathrm{~cm}$ for men and $\geqslant 90 \mathrm{~cm}$ for women plus dyslipidemia (serum triglyceride, $\geqslant 150 \mathrm{mg} \mathrm{dl}^{-1}$; high-density lipoproteincholesterol, $<40 \mathrm{mg} \mathrm{dl}^{-1}$ ) and/or fasting hyperglycemia (plasma glucose, $\geqslant 110 \mathrm{mg} \mathrm{dl}^{-1}$ ) or a diagnosis of diabetes.

\section{Statistical analysis}

Relations between each dietary score and systolic BP (SBP) and diastolic BP (DBP) at baseline were analyzed by multiple regression analysis adjusted for sex, age, previous antihypertensive drugs, and each score of two dietary scores except analysis object. Dietary scores were divided into $1 \mathrm{U}$ per 10-point increase of the sodium dietary score, a two-point increase of the potassium dietary score and a five-point increase of the soybeans/fish dietary score. Changes of BP levels per unit increase were estimated. In addition, to confirm consistency among subgroups regarding the relation between the dietary scores and BP, factors including the presence of MS, sex, age, body weight, body mass index, previous antihypertensive drugs, diabetes, dyslipidemia, smoking habit, drinking habit and fitness habit were assessed by a multiple regression model with interaction terms between dietary scores and each factor. Where a significant interaction was detected, multiple regression analysis was conducted in each subgroup.

The relation between the dietary scores and the prevalence of MS in men and women was analyzed by the Mantel-Haenszel test adjusted by age after each dietary score was dichotomized into the followings: in sodium intake, the highest quartile and lower quartiles of intake group; in potassium intake and soybean/fish intake, the lowest quartile and higher quartiles of intake group. The difference of the relationships between sexes was evaluated by the Breslow-Day test.

BP levels at baseline and at after 6 months of treatment with OLM were collected in the highest/lowest intake groups compared with the other quartiles of each dietary score, and the degree of change in BP at 6 months was compared with baseline. In addition, the changes in the BP levels were compared in highest/lowest intake groups $v s$. the other quartiles of each dietary score by analysis of covariance adjusting for sex, age, body weight, diabetes, MS, baseline BP, drinking habit, smoking habit, and scores of two dietary scores except analysis object.
Statistical analyses were conducted using SAS Release 8.2 (SAS Institute, Cary, NC, USA). All $P$-values are two-sided and those under $5 \%$ were considered statistically significant.

\section{RESULTS}

\section{Baseline patient characteristics}

Table 2 shows baseline characteristics of the 9585 patients (women, $51.4 \%$ ) in this study. The mean age was 64.9 years, and the mean body mass index was $24.7 \mathrm{~kg} \mathrm{~m}^{-2}$. The prevalence of dyslipidemia and diabetes mellitus was 50.8 and $27.8 \%$, respectively. The prevalence of MS in men and women was 48.9 and $19.1 \%$, respectively.

The mean sodium scores for men and women were 18.5 and 17.5, respectively. The mean potassium scores were 2.8 and 3.2 , respectively. The mean soybean/fish scores were 7.6 and 7.9 , respectively.

\section{Relation between dietary score and BP}

Dietary scores were significantly related to BP. Each 10-point increase in sodium corresponded to a $1.8 \mathrm{~mm} \mathrm{Hg}$ increase of SBP and $0.8 \mathrm{~mm} \mathrm{Hg}$ increase of DBP. High sodium intake was significantly related to increased SBP and DBP ( $P=0.0003$ and $P=0.0130$, respectively). Each two-point increase in potassium corresponded with a $1.0 \mathrm{~mm} \mathrm{Hg}$ decrease of SBP and $0.8 \mathrm{~mm} \mathrm{Hg}$ decrease of DBP. High potassium intake was significantly related to decreased SBP and DBP $(P=0.0057$ and $P=0.0005$, respectively). Each five-point increase in soybean/fish corresponded to a $1.2 \mathrm{~mm} \mathrm{Hg}$ decrease of SBP and $0.1 \mathrm{~mm} \mathrm{Hg}$ increase of DBP. High soybean/fish intake was significantly related to decreased SBP $(P=0.0133$ and $P=0.7663$, respectively; Table 3 ).

Regarding SBP, significant interactions were noted between the sodium dietary score and body weight $(P=0.0077)$ or smoking habit $(P=0.0139)$. In addition, for DBP, significant interactions were detected between sodium score and sex $(P=0.0463)$ and between potassium score and drinking habit defined as drinking almost every day $(P=0.0041)$. However, no significant interaction with the soybean/ fish score was detected in any subgroup. 
Table 2 Baseline characteristics of study population

\begin{tabular}{|c|c|}
\hline Parameter & $\mathrm{n}(\%) /$ mean \pm s.d. \\
\hline No. of patients & 9585 \\
\hline Age, years & $64.9 \pm 8.2$ \\
\hline Women & $4929(51.4)$ \\
\hline $\mathrm{BMI}, \mathrm{kg} \mathrm{m}^{-2}$ & $24.7 \pm 3.6$ \\
\hline SBP, mm Hg & $157.4 \pm 17.5$ \\
\hline DBP, $\mathrm{mm} \mathrm{Hg}$ & $88.8 \pm 12.0$ \\
\hline \multicolumn{2}{|l|}{ Hypertension severity } \\
\hline Grade 1 & $4201(43.8)$ \\
\hline Grade 2 & $3160(33.0)$ \\
\hline Grade 3 & $1206(12.6)$ \\
\hline HDL-C, mg dl ${ }^{-1}$ & $57.7 \pm 15.6$ \\
\hline Triglycerides, mg dl ${ }^{-1}$ & $143.5 \pm 94.5$ \\
\hline Fasting blood glucose, $\mathrm{mg} \mathrm{dl}^{-1}$ & $111.7 \pm 36.9$ \\
\hline \multicolumn{2}{|l|}{ Complications/history } \\
\hline Dyslipidemia & $4867(50.8)$ \\
\hline Diabetes mellitus & $2663(27.8)$ \\
\hline Stroke & $360(3.8)$ \\
\hline Percutaneous coronary intervention & $196(2.0)$ \\
\hline Myocardial infarction & $144(1.5)$ \\
\hline \multicolumn{2}{|l|}{ Concomitant medications } \\
\hline Calcium channel blocker & $3586(37.4)$ \\
\hline ARB & $1757(18.3)$ \\
\hline ACE inhibitor & $716(7.5)$ \\
\hline$\beta$-Blocker & $697(7.3)$ \\
\hline Diuretics & $401(4.2)$ \\
\hline \multicolumn{2}{|l|}{ Metabolic syndrome } \\
\hline Men & 2277 (48.9) \\
\hline Women & $943(19.1)$ \\
\hline \multicolumn{2}{|l|}{ Dietary intake scores } \\
\hline \multicolumn{2}{|l|}{ Men } \\
\hline Sodium & $18.5 \pm 3.5$ \\
\hline Potassium & $2.8 \pm 1.0$ \\
\hline Soybeans/fish & $7.6 \pm 1.9$ \\
\hline \multicolumn{2}{|l|}{ Women } \\
\hline Sodium & $17.5 \pm 3.4$ \\
\hline Potassium & $3.2 \pm 0.9$ \\
\hline Soybeans/fish & $7.9 \pm 1.9$ \\
\hline
\end{tabular}

Abbreviations: $A C E$, angiotensin-converting enzyme; $A R B$, angiotensin receptor blocker; $\mathrm{BMI}$, body mass index; DBP, diastolic blood pressure; HDL-C, high-density lipoproteincholesterol; SBP, systolic blood pressure.

High sodium intake was significantly related to increased BP in patients with body weight $<60 \mathrm{~kg}(3.4 \mathrm{~mm} \mathrm{Hg}$ increase of SBP, $P<0.0001)$, non-smokers $(2.8 \mathrm{~mm} \mathrm{Hg}$ increase of SBP, $P<0.0001)$ or women ( $1.4 \mathrm{~mm} \mathrm{Hg}$ increase of DBP, $P=0.0025)$ based on multiple regression analyses in subgroups in which significant interactions were detected. High potassium intake was also significantly related to decreased BP in patients who drink alcohol almost every day (1.1 $\mathrm{mm} \mathrm{Hg}$ decrease of DBP, $P=0.0003$ ).

The relation between dietary scores and the prevalence of MS The prevalence of MS in men with sodium scores $<20$ and $\geqslant 20$ was 47.4 and $52.0 \%$, respectively, at a statistically significant level $(P=0.0026$; Table 4$)$. The prevalence of MS in women with sodium
Table 3 Relation between dietary score and blood pressure

\begin{tabular}{lrccc}
\hline Dietary score & Unit & Estimate & Standard error & P-value \\
\hline SBP (mm Hg) & & & & \\
$\quad$ Sodium & 10 & 1.8 & 0.5 & 0.0003 \\
Potassium & 2 & -1.0 & 0.4 & 0.0057 \\
Soybean/fish & 5 & -1.2 & 0.5 & 0.0133 \\
& & & & \\
DBP (mm Hg) & & 0.8 & 0.3 & 0.0130 \\
Sodium & 10 & -0.8 & 0.2 & 0.0005 \\
Potassium & 2 & 0.1 & 0.3 & 0.7663 \\
Soybean/fish & 5 & & & \\
\hline
\end{tabular}

Abbreviations: DBP, diastolic blood pressure; SBP, systolic blood pressure.

Table 4 Relation between dietary scores and prevalence of metabolic syndrome in men and women

\begin{tabular}{lccc}
\hline & No. (\%) with metabolic syndrome by dietary score & P-value \\
\hline Sodium score & $<20$ & $\geqslant 20$ & \\
Men & $1478 / 3118(47.4)$ & $799 / 1538(52.0)$ & 0.0026 \\
Women & $740 / 3771(19.6)$ & $203 / 1158(17.5)$ & 0.1244 \\
& & \\
Potassium score & $<2$ & $1985 / 4056(48.9)$ & 0.6538 \\
Men & $292 / 600(48.7)$ & $875 / 4666(18.8)$ & 0.0038 \\
Women & $68 / 263(25.9)$ & & \\
\multicolumn{4}{c}{ Soybean/fish score } \\
Men & $<6$ & $2017 / 4135(48.8)$ & 0.7600 \\
Women & $260 / 521(49.9)$ & $849 / 4473(19.0)$ & 0.3881 \\
\hline
\end{tabular}

aHighest intake of sodium was defined as $\geqslant 20$ points (greater than 75 th percentile), whereas lowest potassium and lowest soybeans/fish intake were defined as $<2$ and $<6$ points ( $>25$ th percentile), respectively.

scores $<20$ and $\geqslant 20$ was 19.6 and $17.5 \%$, respectively $(P=0.1244$; Table 4). In men, $48.7 \%$ of those with potassium score $<2$ and $48.9 \%$ of those with potassium score $\geqslant 2$ had MS ( $P=0.6538)$. In women, the proportions were 25.9 and $18.8 \%$, respectively, and the difference was statistically significant $(P=0.0038)$. The difference of these relationships between men and women was statistically significant (sodium score, $P=0.0028$; potassium score, $P=0.0124$ ). No significant relationship was detected between the soybean/fish score and the prevalence of MS in either sex.

\section{Change of SBP/DBP}

Although 6 months of treatment with OLM significantly decreased BP independently of sodium and potassium intake, a significant intergroup difference was detected between patients with high or low soybean/fish score (SBP, $-17.8 \mathrm{~mm} \mathrm{Hg}$ for high score, $-18.5 \mathrm{~mm} \mathrm{Hg}$ for low score, difference $=0.7 \mathrm{~mm} \mathrm{Hg}, P=0.0159$; DBP, $-9.3 \mathrm{~mm} \mathrm{Hg}$ for high score, $-9.9 \mathrm{~mm} \mathrm{Hg}$ for low score, difference $=0.6 \mathrm{~mm} \mathrm{Hg}$, $P=0.0038)$.

\section{DISCUSSION}

In this study, we found significant positive relations between sodium intake and BP and negative relations between potassium or soybean/ fish intake and BP. Our results are consistent with the Intersalt Study, ${ }^{1}$ which found significantly positive relations between 24-h urinary sodium excretion and BP and negative relations between 24-h urinary potassium excretion and $\mathrm{BP}$. 
According to INTERMAP, ${ }^{24}$ although dietary supplements of omega-3 polyunsaturated fatty acid lower BP in hypertensive persons, the effect is small and nonsignificant in normotensive individuals. Increased fish oil intake also reduced BP levels in hypertensive patients in a meta-analysis of interventional trials. ${ }^{25}$ Furthermore, the American Heart Association recommends eating fish to reduce BP. ${ }^{10}$ The present results coincide well with these previous reports.

In the DASH (the Dietary Approaches to Stop Hypertension) $)^{4,26}$ diet eating plan, regular intake of fruits is recommended for hypertensive patients. In this study, we observed significant relations between a high intake of potassium derived from fruit and decreased SBP and DBP, supporting the relation between potassium (fruits) intake and $\mathrm{BP}$ reduction. The relation between the sodium dietary score and BP levels was weaker in men than women, perhaps because more men took antihypertensive drugs than women (52.0 vs. 51.1\%), and medication was started at a lower BP level in men than in women (156.9 vs. $158.0 \mathrm{~mm} \mathrm{Hg}$ ). Interactions were also detected for body weight, smoking habit and drinking habit, which included more men. These distribution differences between men and women likely contributed to the differences in the relations observed in the dietary subgroups.

Six months of treatment with OLM yielded significant BP-lowering effects in all dietary subgroups compared with baseline. Comparing the BP-lowering effects of OLM in the high- vs. low-dietary intake groups revealed a significant difference for only the soybean/fish dietary score. However, the absolute difference was only $<1.0 \mathrm{~mm} \mathrm{Hg}$, suggesting little clinical difference.

In our study, according to the formula from Arakawa et al., ${ }^{21}$ an estimated $3 \mathrm{~g}$ sodium intake increased SBP by $1.8 \mathrm{~mm} \mathrm{Hg}$. This roughly coincides with previously reported values. Kawano et al. ${ }^{5}$ showed that BP decreases by $\sim 1.0 \mathrm{~mm} \mathrm{Hg}$ with a 1-g daily decrease of salt intake in hypertensive subjects. Furthermore, SBP is expected to decrease by $1-4 \mathrm{~mm} \mathrm{Hg}$ with a 3 -g decrease in daily salt intake. ${ }^{12}$

'Health Japan 21' published by the Ministry of Health, Labor and Welfare estimates that the incidence of stroke and ischemic cardiac diseases can be decreased by 6.4 and 5.4\%, respectively, if the general population lowers its SBP by $2 \mathrm{~mm} \mathrm{Hg}^{12}$ If Japanese persons could lower their BP levels by improving their eating habits, small decreases in their BP levels could be clinically significant.

The new guideline for the management of hypertension issued by the Japanese Society of Hypertension ${ }^{12}$ recommends that sodium intake be limited to $<6 \mathrm{~g}$ per day. However, according to the 'Outline for the Results of the National Health and Nutrition Survey Japan $2007,{ }^{13}$ the average daily sodium intake by Japanese men is $11.9 \mathrm{~g}$ and $10.1 \mathrm{~g}$ by women. Therefore, hypertensive patients in particular are recommended to reduce dietary sodium intake. Nonetheless, as Kawano et al. ${ }^{14}$ suggest, precise quantification of dietary sodium is difficult, and thus, it is difficult to identify in whom salt intake targets are achieved.

Considering the above, it may be more effective to inform hypertensive patients of the amount by which they should reduce their daily salt intake, rather than set a total daily limit. The dietary survey questionnaire used in this study indicates that a 10-point decrease in the sodium dietary score corresponds to about a 3-g reduction of salt intake. Thus, it is possible to estimate the amount by which hypertensive patients should decrease their salt intake. The results of this trial may be useful to guide the eating habits in hypertensive patients.

In this sub-analysis, a significantly higher prevalence of MS was found in men in the highest quartile of sodium intake compared with the lower quartiles. Our results support the findings of Hoffmann and Cubeddu, ${ }^{15}$ who reported that subjects with MS have higher 24-h urinary sodium excretion rates than those not meeting diagnostic criteria for MS. Our results also support the findings of Ohta et al., ${ }^{27}$ who reported that 24-h urinary sodium excretion in hypertensive patients with MS was significantly higher than in patients without MS.

It is believed that high BP is the largest contributor to MS in the Japanese general population. ${ }^{28}$ This study supports the idea that BP is strongly related to MS.

A significantly higher prevalence of MS was found in women in the lowest quartiles of potassium compared with women with higher intake. Ohta et al. ${ }^{27}$ previously reported that patients with MS seem relatively unaware of the need to increase consumption of fruit high in potassium content. The present results suggest that the contributors to MS are different for men and women.

Coronary heart disease, CVD and mortality from all causes are significantly elevated in people with high 24-h urinary sodium excretion, independent of other cardiovascular risk factors including blood pressure, ${ }^{29}$ whereas a high-potassium diet exerts a potent protective effect on left ventricular relaxation independent of blood pressure. Sufficient potassium supplementation might be an attractive strategy for cardiac protection, especially in salt-sensitive hypertensive subjects. ${ }^{30}$

This study has several limitations. This was an exploratory analysis, and a prospective clinical study is required to validate these hypotheses. The dietary survey questionnaire we used was closely related to the dietary culture in Japan. Similar surveys conducted elsewhere should also be customized to local dietary habits.

Complete follow-up data from the OMEGA study should clarify relations between the incidence of CVD and lifestyle factors such as sodium, potassium and soybean/fish intake in Japanese patients with hypertension. These data promise to provide useful information to guide treatment in these patients for whom little evidence has been available to date.

In conclusion, clear relations between various dietary intake values and BP and MS were found in Japanese hypertensive patients. Because significant correlations were detected between eating habits and BP in this study, a simple dietary questionnaire may guide hypertensive patients to improve their dietary habits. High sodium intake in men and low potassium intake in women were significantly related to higher prevalence of MS in Japanese hypertensive patients. Six months of treatment with OLM significantly decreased BP independent of sodium and potassium intake.

\section{CONFLICT OF INTEREST}

The authors declare no conflict of interest.

\section{ACKNOWLEDGEMENTS}

We are grateful to all the patients, physicians and medical staff who participated in the OMEGA study. This study was supported by the Daiichi Sankyo.

1 Intersalt Cooperative Research Group. Intersalt: an international study of electrolyte excretion and blood pressure. Results for $24 \mathrm{~h}$ urinary sodium and potassium excretion. BMJ 1988; 297: 319-328.

2 Law MR, Frost CD, Wald NJ. Analysis of data from trials of salt reduction. BMJ 1991; 302: 819-824.

3 Midgley JP, Matthew AG, Greenwood CMT, Logan AG. Effect of reduced dietary sodium on blood pressure: a meta-analysis of randomized controlled trials. JAMA 1996; 275: 1590-1597.

4 Sacks FM, Svetkey LP, Vollmer WM, Appel LJ, Bray GA, Harsha D, Obarzanek E, Conlin PR, Miller III ER, Simons-Morton DG, Karanja N, Lin P-H, Aickin M, Most-Windhauser MM, Moore TJ, Proschan MA, Cutler JA. Effects on blood pressure of reduced dietary sodium and the Dietary Approaches to Stop Hypertension (DASH) diet. N Engl J Med 2001; 344: 3-10. 
5 Kawano Y, Ando K, Matsuura H, Tsuchihashi T, Fujita T, Ueshima H. Report of the Working Group for Dietary Salt Reduction of the Japanese Society of Hypertension: (1) rationale for salt restriction and salt-restriction target level for the management of hypertension. Hypertens Res 2007; 30: 879-886.

6 Staessen JA, Wang JG, Thijs L. Cardiovascular prevention and blood pressure reduction: a meta-analysis. Lancet 2001; 358: 1305-1315.

7 Staessen JA, Wang JG, Thijs L. Calcium-channel blockade and cardiovascular prognosis: recent evidence from clinical outcome trials. Am J Hypertens 2002; 15: 85S-93S.

8 Staessen JA, Wang JG, Thijs L. Cardiovascular prevention and blood pressure reduction: a quantitative overview updated until 1 March 2003. J Hypertens 2003; 21: $1055-1076$.

9 Staessen JA, Li Y, Thijs L, Wang JG. Blood pressure reduction and cardiovascular prevention: an update including the 2003-2004 secondary prevention trials. Hypertens Res 2005; 28: 385-407.

10 Lichtenstein AH, Appel LJ, Brands M, Carnethon M, Daniels S, Franch HA, Franklin B, Kris-Etherton P, Harris WS, Howard B, Karanja N, Lefevre M, Rudel L, Sacks F, Van Horn L, Winston M, Wylie-Rosett J. Diet and lifestyle recommendations revision 2006: a scientific statement from the American Heart Association Nutrition Committee. Circulation 2006; 114: 82-96.

11 Appel LJ, Brands MW, Daniels SR, Karanja N, Elmer N, Sacks FM. Dietary approaches to prevent and treat hypertension: a scientific statement from the American Heart Association. Hypertension 2006; 47: 296-308.

12 Ogihara T, Kikuchi K, Matsuoka H, Fujita T, Higaki J, Horiuchi M, Imai Y, Imaizumi T, Ito S, Iwao H, Kario K, Kawano $Y$, Kim-Mitsuyama S, Kimura G, Matsubara H, Matsuura H, Naruse M, Saito I, Shimada K, Shimamoto K, Suzuki H, Takishita S, Tanahashi N, Tsuchihashi T, Uchiyama M, Ueda S, Ueshima H, Umemura S, Ishimitsu $\mathrm{T}$, Rakugi $\mathrm{H}$, on behalf of The Japanese Society of Hypertension Committee. Japanese Society of Hypertension Committee: the Japanese Society of Hypertension Guidelines for the Management of Hypertension (JSH 2009). Hypertens Res 2009; 32: 3-107.

13 Outline for the Results of the National Health and Nutrition Survey Japan 2008 Available at: http://www.mhlw.go.jp/houdou/2009/11/dl/h1109-1b.pdf.

14 Kawano Y, Tsuchihashi T, Matsuura H, Ando K, Fujita T, Ueshima H. Report of the Working Group for Dietary Salt Reduction of the Japanese Society of Hypertension: (2) assessment of salt intake in the management of hypertension. Hypertens Res 2007; 30: 887-893.

15 Hoffmann IS, Cubeddu LX. Salt and the metabolic syndrome. Nutr Metab CardiovasC Dis 2009; 19: 123-128.

16 Rodrigues SL, Baldo MP, de Sá Cunha R, Andreão RV, del Carmen Bisi Molina M, Gonçalves CP, Danttas EM, Mill JG. Salt excretion in normotensive individuals with metabolic syndrome: a population-based study. Hypertens Res 2009; 32: 906-910.

17 GISSI-Prevenzione investigators. Dietary supplementation with n-3 polyunsaturated fatty acids and vitamin $E$ after myocardial infarction: results of the GISSI-Prevenzione trial. Lancet 1999; 354: 447-455.

18 Bucher HC, Hengstler P, Schindler C, Meier G. N-3 polyunsaturated fatty acids in coronary heart disease: a meta-analysis of randomized controlled trials. Am J Med 2002; 112: 298-304.

\section{APPENDIX}

OMEGA Study Medical Expert Advisory Committee

Medical Advisors: Tamio Teramoto, Toshiro Fujita, Ryuzo Kawamori,

Shigeru Miyazaki.

Statistical Advisor: Satoshi Teramukai.

Chairpersons of each regional committee

Nobuyuki Ura, Keishi Abe, Issei Komuro, Shigehiro Katayama, Satoshi Umemura, Hiroaki Matsuoka, Kazuyuki Shimada, Fumitake
19 Anderson JW, Johnstone BM, Cook-Newell ME. Meta-analysis of the effects of soy protein intake on serum lipids. N Engl J Med 1995; 333: 276-282.

20 Teramoto T, Fujita T, Kawamori R, Miyazaki S, Teramukai S, Igarashi M. OMEGA Study: design, baseline data, metabolic syndrome prevalence in a large-scale observational study of hypertensive patients: the Olmesartan Mega Study to Determine the Relationship between Cardiovascular Endpoints and Blood Pressure Goal Achievement Study. Hypertens Res 2008; 31: 2011-2017.

21 Arakawa K, Matsushita Y, Matsuo H, Ikeda N, Iwashita M, Kuramoto K. Examination of the efficiency of salt taste preference questionnaire in hypertensive patients-results from post marketing surveillance of Olmetec ${ }^{\circledR}$ tablets and Calblock ${ }^{\circledR}$ tablets. Rinsho lyaku 2009; 25: 723-734 (in Japanese).

22 Matsuzawa Y, Kita T, Saitoh Y, Teramoto T, Nakao K, Miyazaki S, Seino Y, Yamada N, Shimamoto K, Katayama S, Kugiyama K, Daida H, Fujita T, Makino H, Ikeda Y, Funahashi T, Nakamura T. Committee to evaluate diagnostic standards for metabolic syndrome: definition and the diagnostic standard for metabolic syndrome. Nippon Naika Gakkai Zasshi 2005; 94: 794-809 (in Japanese).

23 Matsuzawa Y. Metabolic syndrome-definition and diagnostic criteria in Japan. J Atheroscler Thromb 2005; 12: 301.

24 Ueshima H, Stamler J, Elliott P. Food omega-3 fatty acid intake of individuals (total, linolenic acid, long-chain) and their blood pressure: INTERMAP Study. Hypertension 2007; 50: 313-319.

25 Geleijnse JM, Giltay EJ, Grobbee DE, Donders ART, Kok FJ. Blood pressure response to fish oil supplementation: metaregression analysis of randomized trials. J Hypertens 2002; 20: 1493-1499.

26 Appel LJ, Moore TJ, Obarzanek E, Vollmer WM, Svetkey LP, Sacks FM, Bray GA, Vogt TM, Cutler JA, Windhauser MM, Lin PH, Karanja N. A clinical trial of the effects of dietary patterns on blood pressure. DASHCollaborative Research Group. N Engl J Med 1997: 336: 1117-1124.

27 Ohta Y, Tsuchihashi T, Arakawa K, Onaka U, Ueno M. Prevalence and lifestyle characteristics of hypertensive patients with metabolic syndrome followed at an outpatient clinic in Fukuoka, Japan. Hypertens Res 2007; 30: 1077-1082.

28 Kobayashi J, Nishimura K, Matoba M. Generation and gender differences in the components contributing to the diagnosis of the metabolic syndrome. Circ J 2007; 71: 1734-1737.

29 Tuomilehto J, Jousilahti P, Rastenyte D, Moltchanov V, Tanskanen A, Pietinen P, Nissinen A. Urinary sodium excretion and cardiovascular mortality in Finland: a prospective study. Lancet 2001; 357: 848-851.

30 Matsui H, Shimosawa T, Uetake Y, Wang H, Ogura S, Kaneko T, Liu J, Ando K, Fujita T. Protective effect of potassium against the hypertensive cardiac dysfunction: association with reactive oxygen species reduction. Hypertension 2006; 48: 225-231.

(c)

This work is licensed under the Creative Commons Attribution-NonCommercial-Share Alike 3.0 Unported License. To view a copy of this license, visit http://creativecommons.org/ licenses/by-nc-sa/3.0/

Gejyo, Kiyotaka Kugiyama, Uichi Ikeda, Toyoaki Murohara, Toru Kita, Shigeo Takata, Masashi Kobayashi, Toshio Ogihara, Shuji Arima, Mitsuhiro Yokoyama, Masayasu Matsumoto, Masunori Matsuzaki, Jitsuo Higaki, Yoshinori Doi and Kikuo Arakawa.

Administrative Office: Post-Marketing Study Department, DaiichiSankyo (Tokyo, Japan). 